\title{
Advancing women's health
}

Population Council

Follow this and additional works at: https://knowledgecommons.popcouncil.org/ series_newsletters_momentum How does access to this work benefit you? Let us know!

\section{Recommended Citation}

"Advancing women's health," Momentum newsletter. New York: Population Council, 2014. 


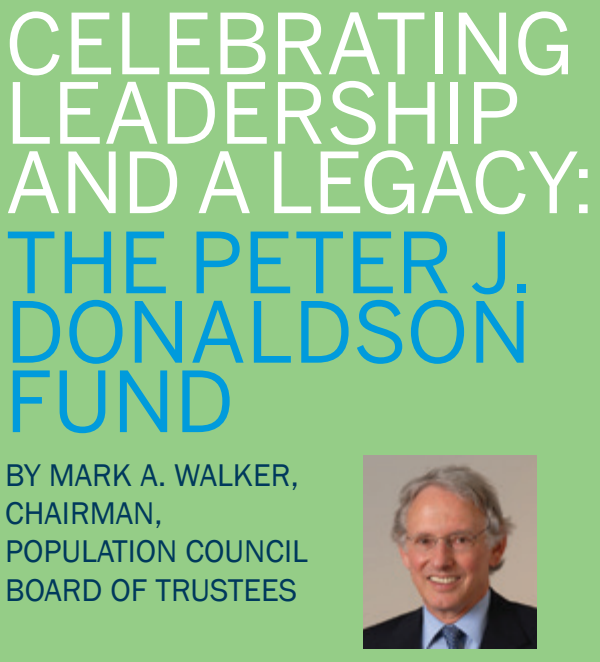

In this issue of Momentum we honor Peter Donaldson, who is retiring as President of the Population Council after a distinguished career in international development and 10 years as Council president. Under Peter's leadership, the Council has increased its influence globally to ensure that evidence informs policies and programs.

- Adolescent girls are getting more attention, in part because Council researchers have emphasized the importance of this underserved group.

- National governments in Africa and Asia have adopted Councilrecommended policies for addressing the neglected health needs of men who have sex with men and injecting drug users.

- Continuing a tradition of groundbreaking biomedical research, the Council will soon seek approval from the U.S. Food and Drug Administration for a novel one-year contraceptive vaginal ring that will expand contraceptive choice and improve women's health.
These accomplishments, among many others during Peter's tenure, have played a prominent role in shaping population, health, and development programs and policies.

This issue of Momentum highlights the Population Council's leadership in women's health and family planningand a few of the many researchers behind it.

This issue is a fitting homage to Peter. Peter's career began in 1971 as a fellow at the Institute for Population and Social Research at Mahidol University in Bangkok. Two years later, Peter joined the Population Council in Bangkok, where he was based at the Thai Ministry of Public Health. In both positions Peter's research supported one of the earliest, most successful national family planning programs. Like Peter, Council researchers today are leaders in generating and using evidence for program and policy change.

Peter is dedicated to strengthening developing country organizations through the professional development of researchers. He believes a critical task of the Council is to build the capacity of scientists and researchers who can become national and international leaders in their fields. In appreciation of his many contributions, the Board of Trustees has created "The Peter J. Donaldson Fund" to advance the leadership of developing country researchers concerned with population, health, and development. 

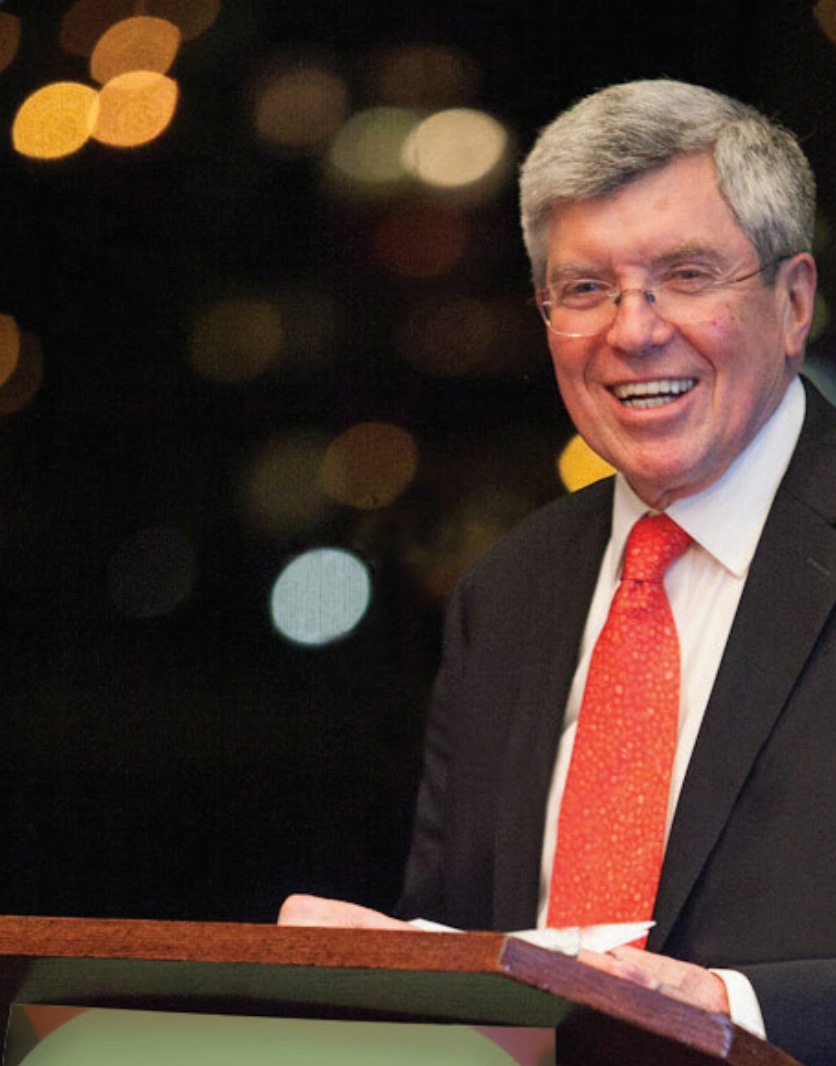

SUPPORT THE

PETER J. DONALDSON

FUND BY RETURNING

THE ENCLOSED ENVELOPE.

FOR MORE INFORMATION, CONTACT DEVELOPMENT@ POPCOUNCIL.ORG OR 877-339-0500.

THANK YOU. 


\section{A DEDICATION TO BUILDING OF SCIENTISTS AND RESEAR}

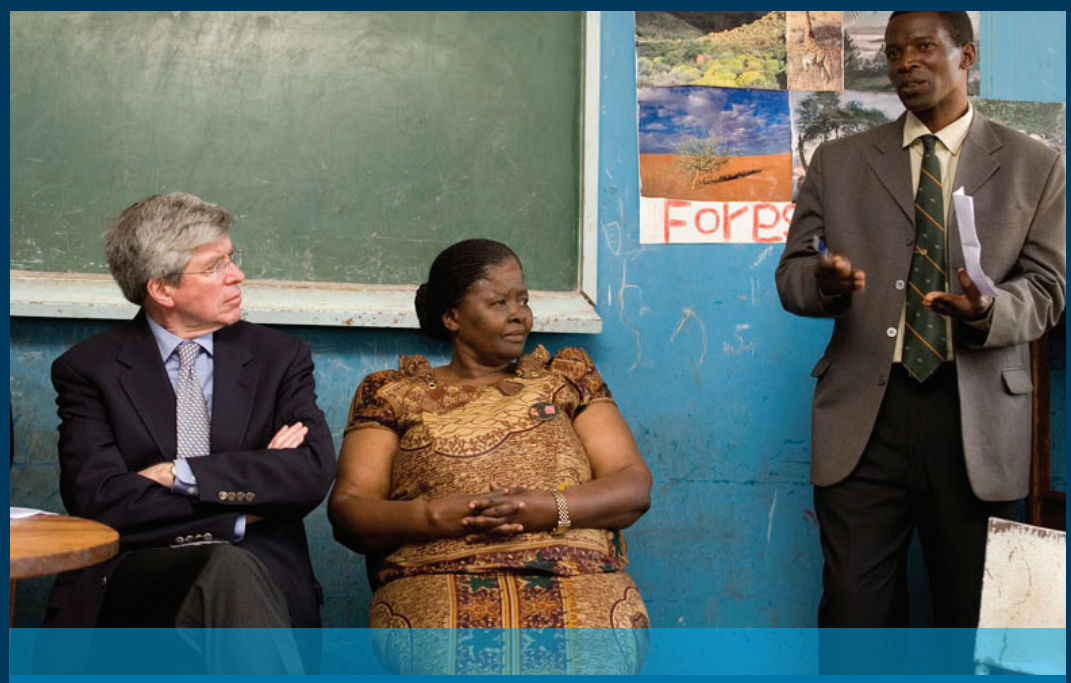

Discussing sexual and gender-based violence prevention efforts in Zambia. Read more on page 2.

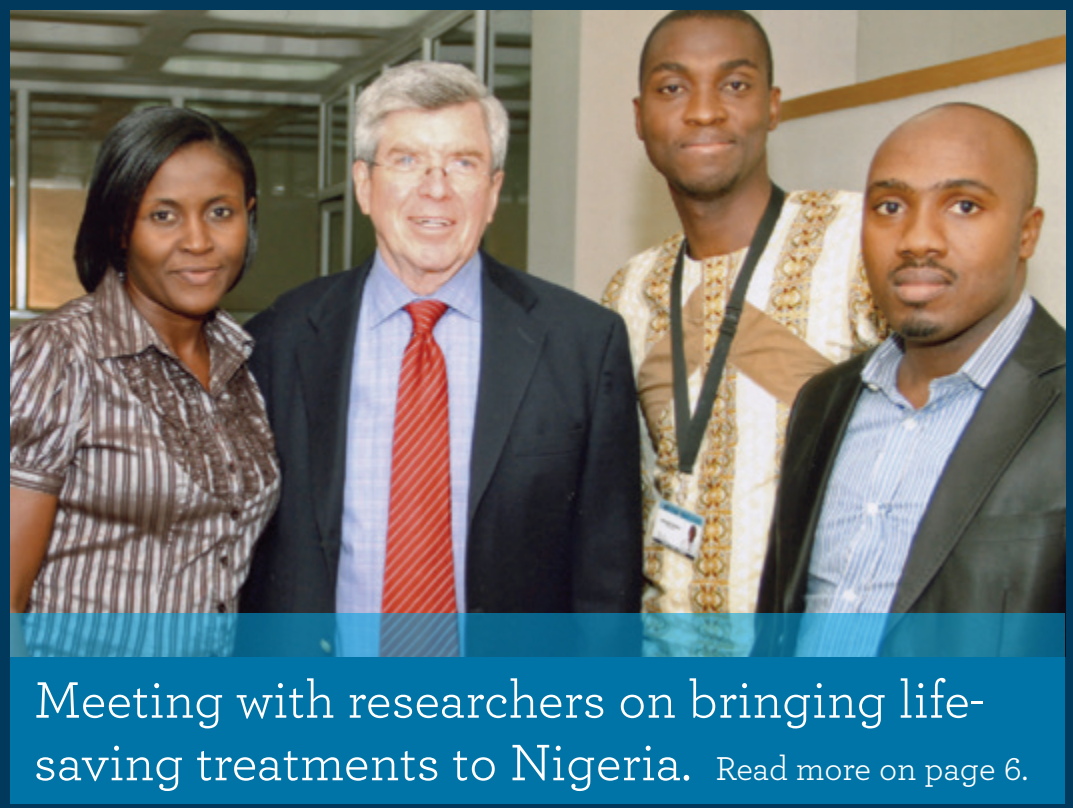




\section{THE CAPACITY CHERS}
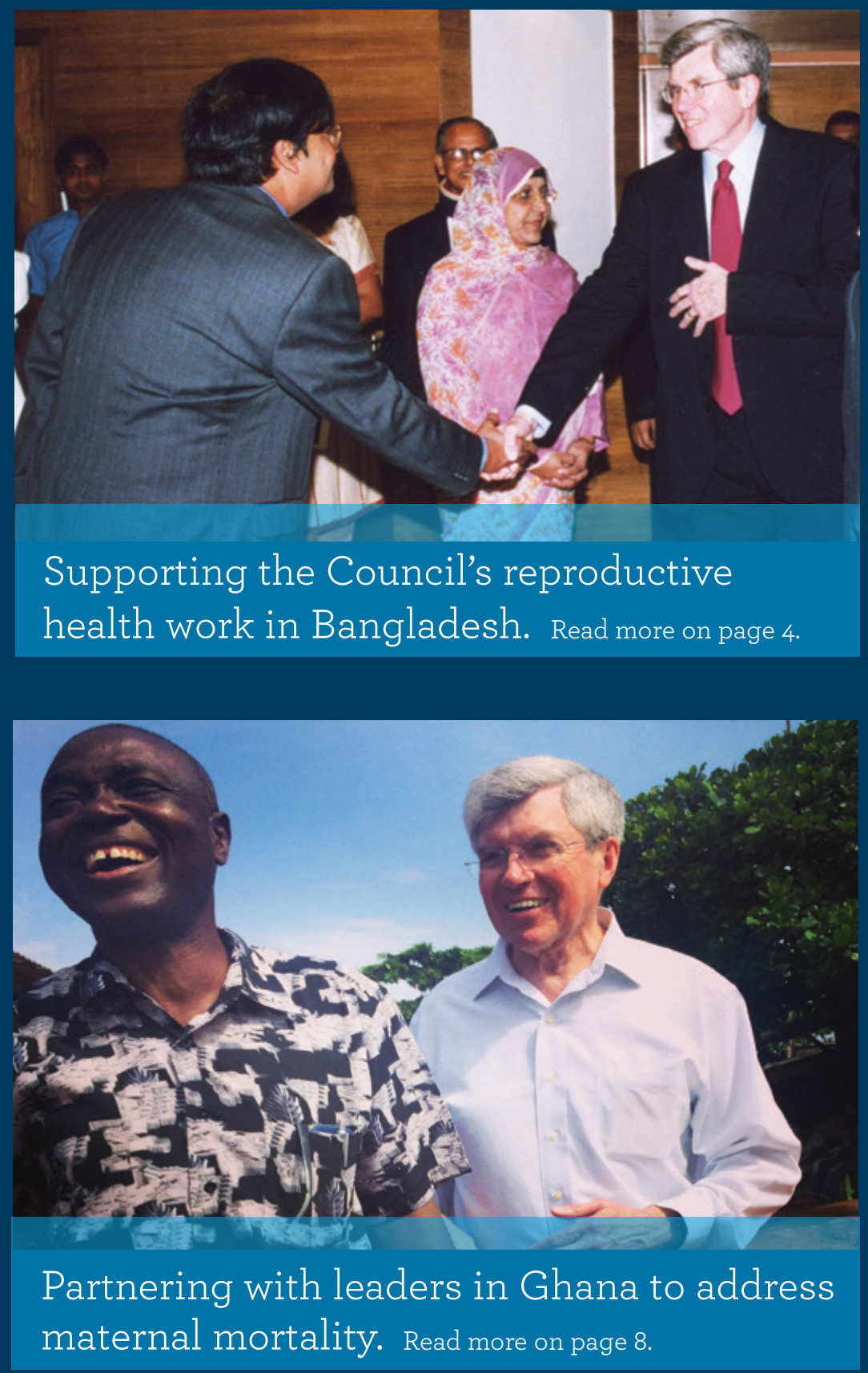


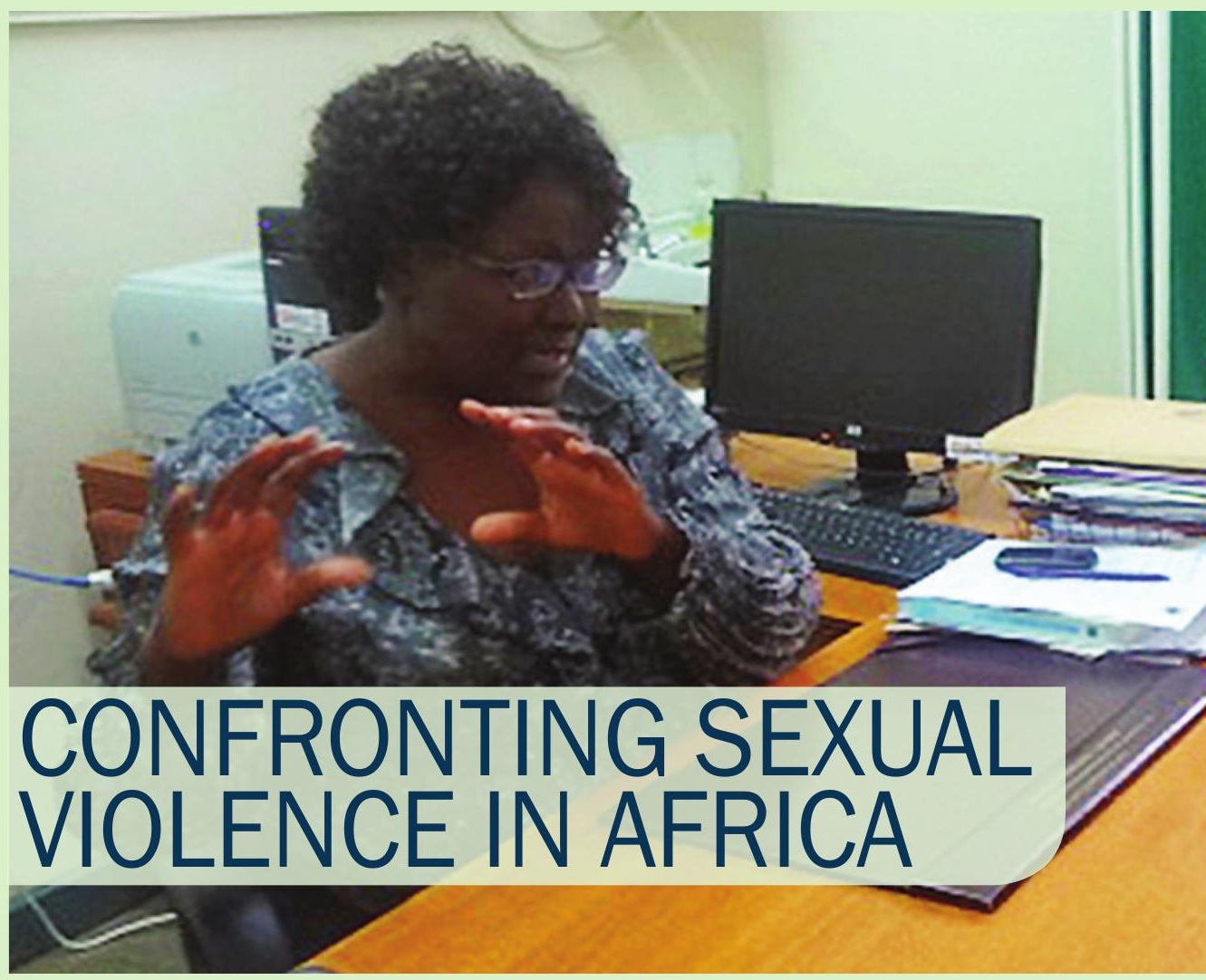

THE PROBLEM According to the US Agency for International Development, one out of three women worldwide will be beaten, coerced into sex, or otherwise abused in her lifetime, with rates of abuse reaching 70 percent in some countries. The World Health Organization reports that Africa has the highest prevalence of sexual and genderbased violence.

\section{THE PROGRESS The Population}

Council and its partners are developing interventions to address sexual violence in low-resource settings in Africa where access to care is limited. Researchers are working to improve the medical management of violence, facilitate more effective criminal justice responses to all cases, and reduce levels of sexual and gender-based violence at the community level. "We began this work because there was no strong, regional evidence base on sexual violence programming in subSaharan Africa. The only strategies available were developed for high-resource settings such as Europe and the United States," says the Council's Chi-Chi Undie. Undie began the Africa Regional SGBV Network, a partnership that works in five East and Southern African countries to improve response and prevention services and to influence programming and policies ensuring that women who suffer from sexual violence have much-needed support. The project employs a network strategy to identify solutions efficiently. 


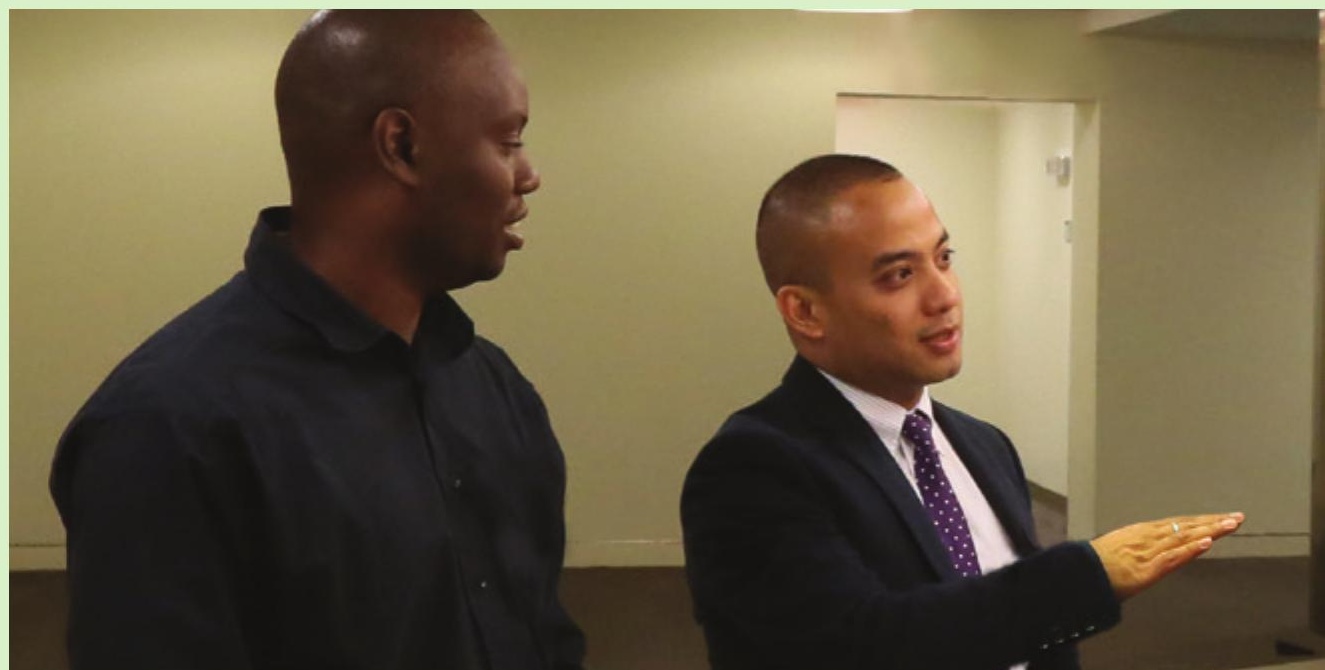

IMPROVING WOMEN'S HEALTH THROUGH VOUCHER PROGRAMS

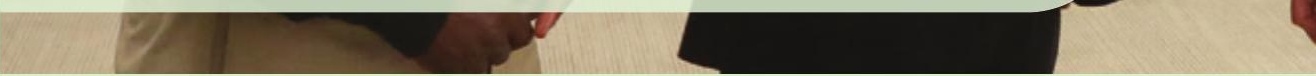

THE PROBLEM Each year nearly 300,000 women worldwide die from preventable causes related to pregnancy and childbirth, and 5.6 million babies are stillborn or die as newborns. Many of these deaths could be prevented if more women had access to adequate maternity care and family planning services. Voucher programs are being implemented by governments and private agencies in low- and middle-income countries to give poor women access to high-quality, subsidized care at accredited providers.

\section{THE PROGRESS In Bangladesh,}

Cambodia, Kenya, Tanzania, and Uganda, the Population Council is evaluating voucher programs that provide mater- nity care, family planning services, STI treatment, post-rape care, and-in Cambodia-legal abortion services. "We're working with ministries of health, implementing partners, and research organizations to better understand the effectiveness of these voucher programs," says Ashish Bajracharya, who began his career at the Council as a Fred H. Bixby postdoctoral fellow in New York City. "Our results will help the public and private entities that manage voucher programs decide whether and how to expand the programs or to investigate other health care financing options."

THE IMPACT Council research found that the reproductive health voucher pro- 


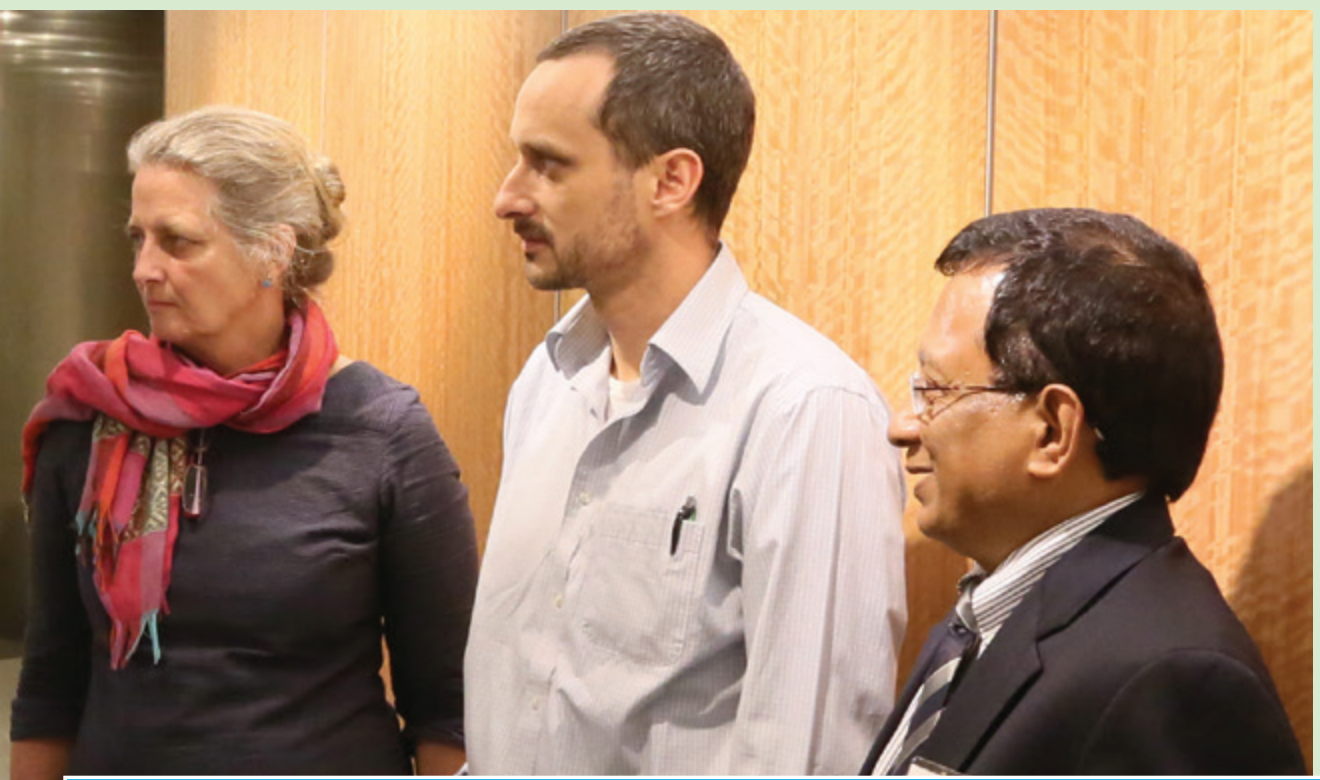

Ashish Bajracharya (SECOND FROM LEFT), a social demographer and policy analyst in the Council's Bangladesh office, understands the need for evidence on whether voucher programs improve equitable access to, use of, and quality of health care services.

gram in Bangladesh increased the use of safe motherhood services. The study showed that the proportion of women delivering in a facility in areas where vouchers were available was 8 percentage points higher than in comparison areas where vouchers were not available. Similarly, proportions of women attending four or more antenatal care visits and using postnatal care services were higher-by 8 and 14 percentage points, respectively-in areas with vouchers compared to control areas. In Cambodia the evaluation measured an increase in the uptake of long-term contraceptive methods among women using vouchers that was 4 percentage points higher than among women who did not use vouchers.
"All of the programs in the five countries have increased access and utilization," says Bajracharya. "Using our data, we are comparing different program structures across countries to see where and how vouchers can improve maternal health."

DONORS AND PARTNERS The Bill \& Melinda Gates Foundation; Action for Health; African Population and Health Research Center, Kenya; Bangladesh Ministry of Health and Family Welfare; Cambodia Ministry of Health; Cambodia National Institute of Public Health; EPOS Health Management; German Development Bank (KfW); Ifakara Health Institute; Kenya Ministry of Health; Marie Stopes Uganda; Mbarara University of Science and Technology, Uganda; PricewaterhouseCoopers; Tanzania National Health Insurance Fund; Uganda Ministry of Health; UK Department for International Development; USAID; The World Bank/Global Partnership on Output-Based Aid; World Health Organization 



THE PROBLEM One of the leading worldwide causes of maternal death is high blood pressure during pregnancy-including seizures associated with severe preeclampsia and eclampsia. Most of these deaths could be prevented by ensuring that women receive treatment as soon as symptoms develop. Magnesium sulfate $\left(\mathrm{MgSO}_{4}\right)$ is recommended by the World Health Organization as the most effective, safe, and low-cost medication for severe preeclampsia and eclampsia, and several national health protocols recommend its use. In practice, however, the drug is not always available at the primary care level and not all providers have been trained to administer it correctly.

\section{THE PROGRESS The Population}

Council conducts research and educates policymakers about how to improve availability and correct use of $\mathrm{MgSO}_{4}$ to reduce the possibility of women dying from seizures in resource-poor settings.

In Kano State, Nigeria, the Council assessed healthcare providers' acceptance of $\mathrm{MgSO}_{4}$, the training required and capacity-building support needed to introduce the drug in hospitals, and the factors influencing referral of patients with eclampsia for treatment. These efforts culminated in the development and introduction of a Council curriculum for health service providers.

In Bangladesh and Mexico, ongoing Council research seeks to expand provision of the drug by community-level service providers and identify ways to increase providers' 


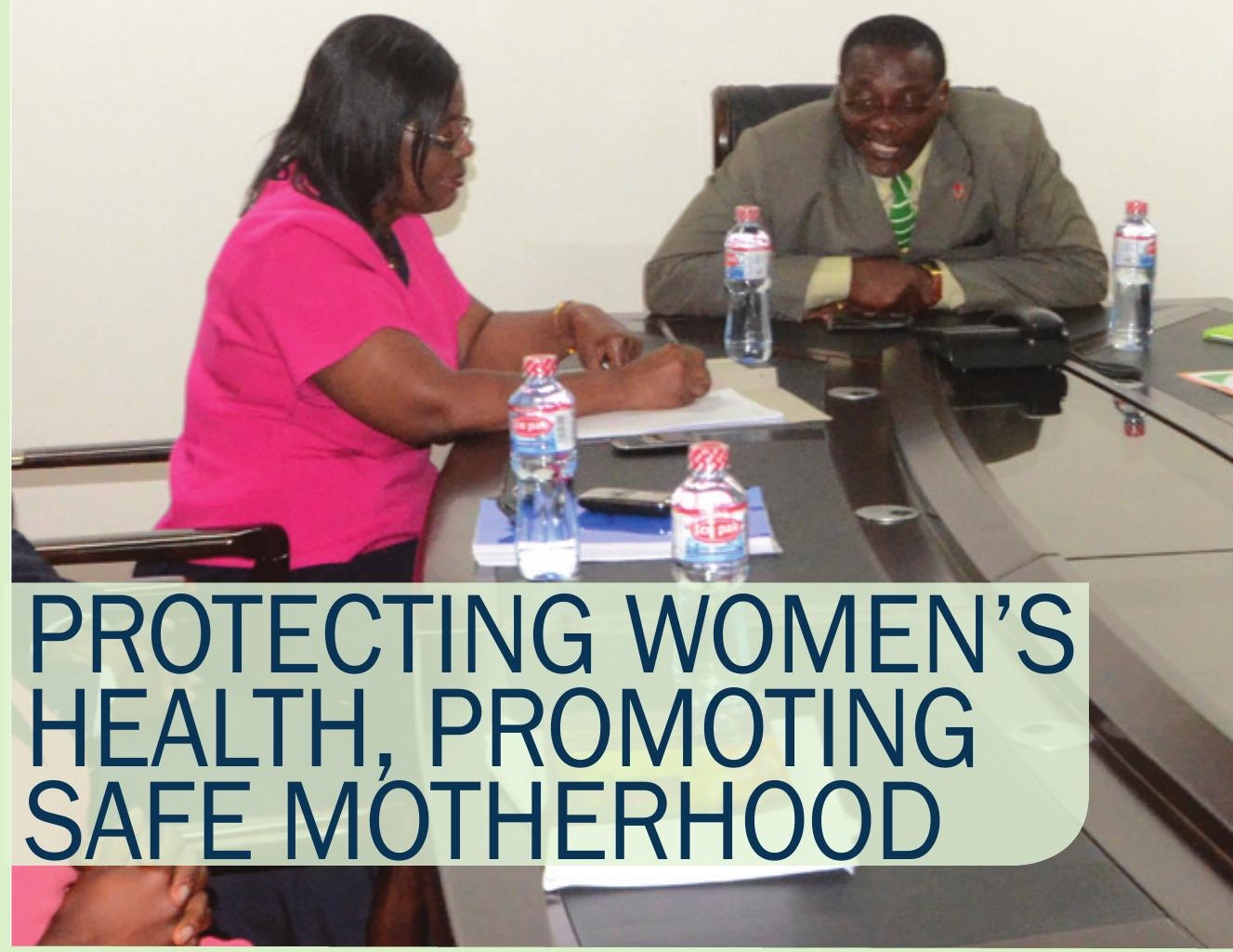

THE PROBLEM Ghana has a progressive public health system, but women who live in urban slums and remote rural communities have limited access to maternal health care. Maternal mortality is the secondleading cause of death among women in Ghana, and while abortion is legal in Ghana, more than one in ten maternal deaths result from complications related to unsafe abortion.

\section{THE PROGRESS The Council-} led R3M program (Reducing Maternal Morbidity and Mortality) is helping the
Government of Ghana and the Ghana Health Service improve access to lifesaving family planning services and safe, comprehensive abortion care. “Despite progressive laws, family planning and safe abortion are sensitive issues in Ghana, which still has a very traditional culture," says Gertrude Nsorma Nyaaba. "So, in addition to improving services, R3M is working to create conducive environments by educating communities, providers, the police, and policymakers about the legality and life-saving effects of reproductive health care." 


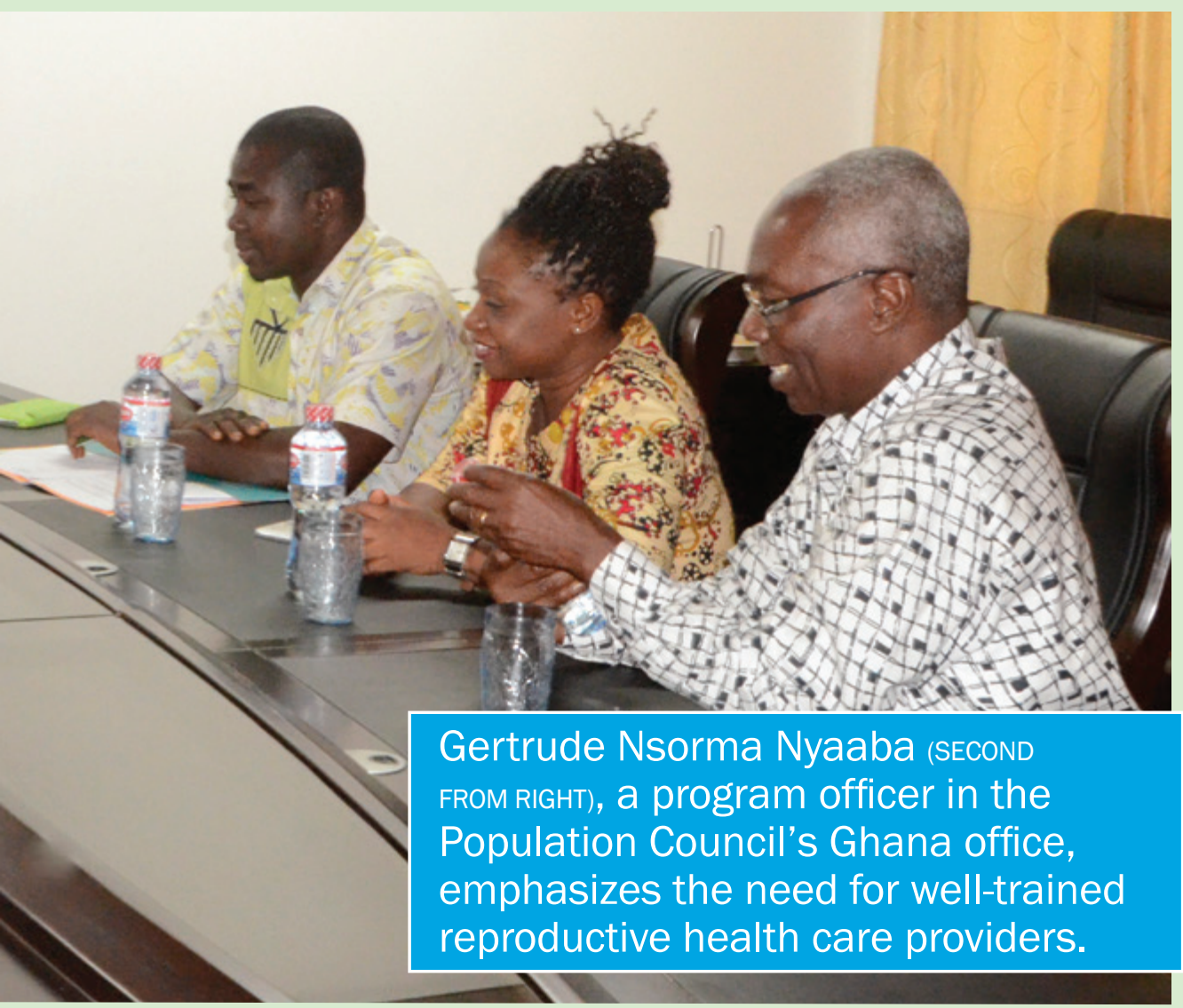

THE IMPACT As of December 2013 nearly a million women had received modern family planning methods through R3M. The program has also trained more than 700 healthcare providers. Best practices from R3M are being evaluated so that the program can be expanded and replicated in other regions. "Maternal health is a human rights issue," says Nsorma. "No woman should die giving birth. I grew up in a poor region of Ghana, and I see how family planning can benefit women, families, and communities. Spacing pregnancies and improving maternal health help reduce the stress around providing security for families, leading to happier, healthier, and more financially sound individuals and families. These families can then contribute to strong and stable communities and countries."

DONORS AND PARTNERS Anonymous; EngenderHealth; Ipas; Marie Stopes International; Willows Foundation 


\section{ANRUDH JAIN}

DISTINGUISHED SCHOLAR AT THE POPULATION COUNCIL

Anrudh Jain has been a leading thinker in population and family planning for almost five decades and has contributed seminal research and writing to create important policy and program change, particularly in quality of care, unmet need for family planning, and HIV risk reduction.

\section{What are the biggest challenges currently facing family planning programs?}

Many family planning programs in East Asia and Latin America have done a good job of satisfying unmet need. Today we need to develop programs that provide methods appropriate for women throughout their reproductive lives, particularly in South Asia and sub-Saharan Africa.

\section{Your most recent research is on the best ways to reduce unmet need for family planning.}

When women become dissatisfied with their contraceptive method, they may discontinue using it and may stop using contraception altogether instead of switching to another method. For example, 74 percent of women in Bangladesh and 82 percent of women in the Dominican Republic who wanted to avoid pregnancy but were not using a contraceptive had actually used a method in the past. Most family planning programs address unmet need by helping women initiate contraceptive use. Few programs pay attention to women's needs after they've begun using a method.

\section{How can this be addressed?}

The most effective way to reduce unmet need for contraception is to make sure women have a method that they like, and that they will continue using it or switch to another method. This can be done by expanding access to a broad range of family planning methods; helping women select methods that are most appropriate for their current reproductive needs and lifestyle; providing women with accurate information about side effects so that they know what to expect and how to manage them; and encouraging them to switch methods as their needs, circumstances, or preferences change over time.

This isn't a new idea, but it needed to be introduced to a new generation of public health researchers. I talked about this in 2013 at the International Conference on Family Planning in Addis Ababa, and I think it was an "A-ha!" moment for many.

Ensuring sustained use of contraception requires improving quality of care and the information we provide to women whenever they come into contact with contraceptive services. Doing this can have a big impact on helping women have the number of children they want, when they want them, and safeguarding their health and well-being. 
I first became interested in the

Population Council while studying at Middlebury College. After taking classes in international development, I began to appreciate how central contraceptive choice and access are to social and economic development as well as to the future of our planet. I read some of the Population Council's research and was impressed by the organization's commitment to global impact through scientific investigation. A family friend introduced me to the Council's president, Peter Donaldson, and he was kind enough to meet with me, a nervous college junior. I ended up interning at the Council for the summer.

That summer I realized the Council is much more than a ground-breaking research institution-it's a community of driven professionals who care deeply about the organization's research, impact, quality of work, and their fellow colleagues. After graduating in 2010 and living abroad, I joined the Council full time in 2011, working with social scientists around the world and our biomedical staff at the Center for Biomedical Research. It was inspiring to be surrounded by colleagues solving some of the world's toughest health and development problems.

\section{WHY I GIVE TO THE POPULATION COUNCIL}

As a Population Council donor, I feel privileged to have worked there during the start of my career. I had the opportunity to interact with scientists and researchers who are national and international leaders in the fields of population, health, and development. I learned that even the most challenging global problems can be solved with a careful combination of ambition, analysis, creativity, and a sense of humor. Donating to the Council helps ensure that men and women have an ever-growing array of family planning options to meet their needs. It also supports pioneering research that leads to policy changes around the world. The Population Council's work has tangible impact from Mexico to Bangladesh to your corner pharmacy. I encourage my peers and others to give to the Council because it is the hub for innovation and positive global change. 





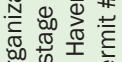

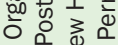

莌宁

iे

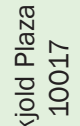

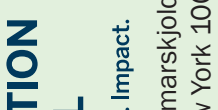

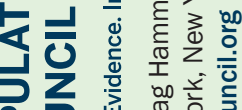



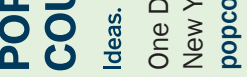

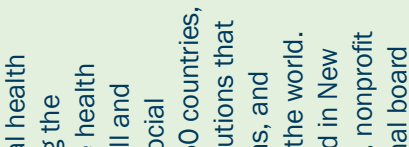
त 语

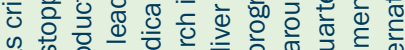
की के

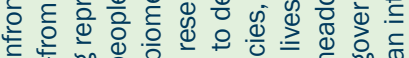
당 का

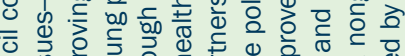

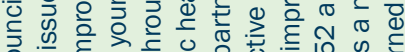

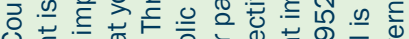

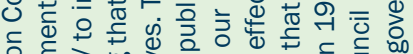

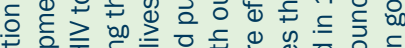

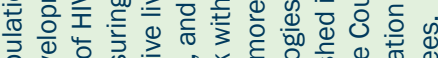

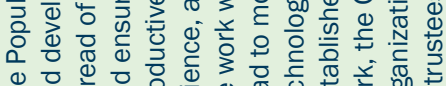

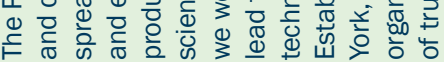
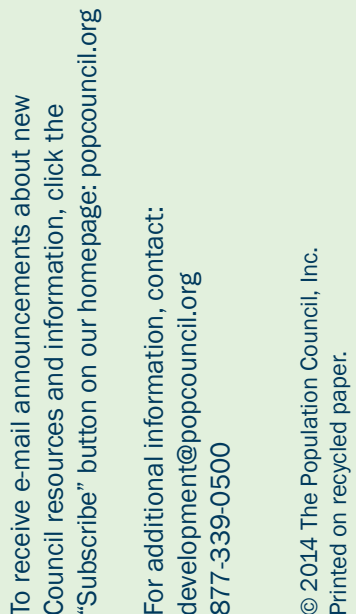